\title{
O Movimento Sem Terra e os Governos Lula: Da Utopia e do Pragmatismo
}

\author{
Bruno Bernardes* \\ * Observatório Político, Portugal; goncalvesbernardes@gmail.com
}

\begin{abstract}
Resumo
O presente artigo explica a relação entre o Movimento dos Trabalhadores Rurais sem Terra (MST) e o Partido dos Trabalhadores (PT) no Brasil. Argumenta-se que a estratégia de inserção do MST na luta político-partidária do PT foi construída de forma pragmática conquanto insere-se no contexto eleitoral e na vitória de Lula da Silva nas presidenciais de 2002. No contexto brasileiro, a relação entre partidos e movimentos sociais tem sido citada como uma relação de dependência. No entanto, analisando-se a relação do MST com os governos de Lula da Silva observa-se que este conseguiu gerir a sua relação com o PT através de uma inserção pragmático-ideológica.
\end{abstract}

Palavras-chave: Brasil; Partido dos Trabalhadores; movimentos sociais; Governo Lula

\begin{abstract}
The article explains the relationship between the Landless Rural Workers Movement (MST) and the Workers' Party (PT) in Brazil. It is argued that the strategy of the MST within the PT's political party struggle was built in a pragmatic way, being a significant partner in the victory of Lula da Silva in the presidential elections of 2002. In the Brazilian context the relation between parties and social movements has been quoted as one of dependence. However, by analyzing the relationship of the MST with the governments of Lula da Silva, it can be concluded that the latter managed its relationship with the PT through a pragmatic-ideological insertion.
\end{abstract}

Keywords: Brazil; Workers Party; social movements; Lula Government 


\section{Introdução}

Durante décadas a América Latina tem sido considerada a região mais desigual do mundo (Ffrench-Davis, 2005; Munck, 2007; Patrício, 2012). Os sucessivos modelos de desenvolvimento produziram contradições e paradoxos políticos difíceis de ultrapassar na governação da região. O antigo modelo de substituição de importações implantado entre as décadas de 1930 e 1940 permitiu firmar um contrato social entre as diversas forças sociais e políticas (Patrício, 2012). Com o eclodir das crises da dívida e os processos de redemocratização na segunda metade da década de 1980, os Estados latino-americanos iniciaram processos de abertura das suas economias, com uma inserção internacionalista, direcionada para a privatização e para estratégias monetaristas (Ffrench-Davis, 2005; Munck, 2007; Patrício, 2012). Este regime económico tido como solução à multiplicação das crises da dívida, acabaria por resultar no aprofundamento da desigualdade, na geração de bolsas de pobreza e nas altas taxas de desemprego formal compensado pelo trabalho informal (Ffrench-Davis, 2005).

Sendo uma das dez maiores economias o Brasil é também um dos dez países mais desiguais do mundo em distribuição de rendimentos (Ffrench-Davis, 2005; Malamud, 2009; Patrício, 2012). Apesar do crescimento da classe média e do aumento do poder de compra, os problemas da desigualdade estrutural denotam uma enorme diferenciação entre classes e grupos sociais, com os $10 \%$ mais ricos a possuir cerca de $45 \%$ da riqueza, enquanto os $20 \%$ mais pobres possuem menos de $3 \%$ da riqueza brasileira (UN Development Report, 2013). O Brasil apresenta uma configuração histórica oligárquica e patrimonial com uma enorme concentração de património e propriedade num pequeno grupo de pessoas (Patrício, 2012). O processo de modernização e de introdução das estruturas do capitalismo e o processo de democratização não alteraram a concentração de terras com cerca de 1,5\% de proprietários a controlar $47 \%$ da terra arável do Brasil, enquanto um terço de agricultores possuem 1,5\% do total de terras (Teubal, 2009; Carter, 2010).

O mundo rural brasileiro é paradoxal. As condições geográficas, políticas e económicas produziram um rápido processo de urbanização durante todo o século xx, aliado à industrialização (Rodgers et al., 2012, pp. 3-4). Este processo de urbanização, um dos mais rápidos que o mundo testemunhou, produziu um intenso e profundo êxodo rural (Gilbert, 1994; Kamper, 2002). Este infligiu a desertificação de pessoas e de atividade económica baseada em sistemas de subsistência e de pequena propriedade rural, levando a alterações nas diferentes economias regionais e estaduais. A terceirização das novas populações urbanas e suburbanas, contrasta com a industrialização da agricultura e do agronegócio aliados à estratégia nacional de exportação de commodities (Malamud, 2009; Patrício, 2012). Esta economia altamente industrializada e virada para os mercados interno e externo contrasta com a existência de uma população pobre que vive abaixo da linha de pobreza. Enquanto o Brasil se afirmou como líder mundial na exportação de açúcar, laranjas, soja, açúcar ou carne de vaca durante os governos Lula, cerca de 25 milhões de brasileiros sofreu de fome nos últimos anos (World Bank, 2005; IPEA, 2005). Com um quinto da sua 
população a viver no campo e a trabalhar na agricultura, o Brasil continua com entre 3 a 6 milhões de famílias sem terra, enquanto a terra arável não produtiva constitui mais de um quarto do território nacional (Carter, 2010; Carter \& Carvalho, 2010).

Neste contexto, insere-se o papel de mobilização, contestação e participação política dos movimentos sociais na América Latina no período da redemocratização e da ascensão de novos grupos sociais. Um dos exemplos paradigmáticos tem sido o Movimento dos Trabalhadores Rurais Sem Terra (MST) no Brasil. Enquadrado numa série de outros movimentos de trabalhadores rurais sem terra, como no caso da Índia, o MST nasceu com a "encruzilhada natalino" de 1981, uma ocupação efetuada no Rio Grande do Sul e que deu origem a um acampamento, símbolo do movimento anti ditadura. Viria a institucionalizar-se na década de 1980 mas com raízes históricas na confrontação ao sistema patrimonialista-estamental brasileiro e à lei de terras de 1850 (Faoro, 2001; Carter, 2010). A partilha de terras tem mobilizado a participação dos trabalhadores rurais na contestação política, demonstrando o peso desta problemática na agenda política brasileira e apresentando-se como exemplo de movimento da sociedade civil inúmeras vezes citado (Teubal, 2009; Carter, 2010; Stahler-Shock \& Vanden, 2011).

Com o processo de democratização e a consolidação das instituições na América Latina, o MST surgiu como um movimento de contestação, primeiro à ditadura militar, e agora como contra-poder às políticas públicas na distribuição de terras. Aliado desde a década de 1980 ao Partido dos Trabalhadores (PT), o MST depositou esperanças na eleição presidencial de Lula da Silva. No entanto, logo no primeiro mandato o MST e o governo incompatibilizaram-se. Nesse sentido, procuramos explicar esta incompatibilização e o papel que o MST ocuparia nos dois mandatos presidenciais de Lula, explicando alterações organizacionais e novas formas de organização emergentes na década de 2000.

\section{Considerações Metodológicas e Teóricas}

Para o presente artigo, pretendemos responder à seguinte questão: como é que o MST desenvolveu a sua estratégia de contestação e mobilização política durante os governos Lula?

O objetivo da presente investigação será o de descrever e explicar (Blaikie, 2010) o redesenho da estratégia de contestação e mobilização do MST face (1) à alteração ideológica e programática do PT aquando da vitória eleitoral de Lula da Silva e (2) no tipo de adaptação estratégica do MST face à sua programática ideológica. Neste sentido, pretendemos:

a) Enquadrar o MST nas teorias da sociedade civil, tendo em atenção o seu papel de mobilização e contestação, primeiro através de uma descrição da sua história e cultura institucionais, e segundo, a partir de uma descrição da sequência do seu programa político e da mobilização de rua; 
b) Identificar as alterações ideológicas e programáticas no PT entre os finais da década de 1990 e os inícios de 2000 e a resposta organizacional e ideológica do MST.

Por forma a descrever e analisar o papel de mobilização e contestação do MST durante os dois mandatos presidenciais de Lula da Silva (2003-2010), recorremos a uma abordagem qualitativa (Blaikie, 2010), centrada primeiro no desenvolvimento histórico e institucional do MST, segundo na estratégia delineada pelo movimento em conjugação com a evolução ideológica do PT e, terceiro, o papel do MST na contestação à feitura de políticas de terras dos dois governos liderados por Lula da Silva. O método qualitativo terá por base uma estratégia indutiva (Blaikie, 2010) que procura, por um lado, descrever e analisar a transformação ideológica e programática do PT, e por outro lado, pelo tipo de mobilização e contestação do MST.

Paralelamente, consideramos que a conceção ideológica dos movimentos sociais acompanha uma visão pragmática da sociedade política. Seguindo Chantal Mouffe e Ernesto Laclau (1985) - e contrariamente à conceção generalizada de que os movimentos sociais e os discursos ideológicos não são pragmáticos - no presente artigo teremos em atenção o cruzamento entre os discursos ideológicos e a conceção pragmática da política enquanto estratégia quotidiana dos movimentos sociais.

O pragmatismo dos movimentos sociais depende do grau de injustiça sentido, da conjuntura e contexto da temática, e da capacidade de autonomização organizativa dos cidadãos envolvidos. Neste sentido, advoga-se um conceito de sociedade civil que impõe a existência de uma esfera pública onde os interesses dos indivíduos e das diferentes coletividades e grupos vivem e dão corpo às paixões, às ideias, à reivindicação, às exigências face ao Estado e outras instituições políticas e não políticas (Costa, 2013).

A emergência dos movimentos sociais não só aponta para a definição de novas estratégias de protesto social, como são indicativos de um retorno da política de rua que apresenta uma alternativa à política institucionalizada e novas respostas aos problemas da democracia representativa, evidentes no declínio das lealdades partidárias, na diminuição do Estado e no desenvolvimento de várias formas de globalização e de governança (Della Porta \& Diani, 2011).

\section{A Relação entre Movimentos Sociais e Partidos}

Desde a década de 1990 que o conceito de sociedade civil passou para o centro do debate político ocidental ocupando um lugar cimeiro no discurso político e partidário, assumindo um caráter quase messiânico na solução dos problemas que enfrentam as democracias contemporâneas. Para a grande parte dos autores, sociedade civil refere-se a uma "densa rede de grupos, comunidades, redes e laços que se estabelecem entre o indivíduo e o Estado moderno" (Kenny, 2014, p.1). Esta definição de sociedade civil tornou-se bastante comum entre teóricos liberais da democracia, para quem uma sociedade civil é saudável conquanto advogue independência ou autono- 
mia face ao Estado. No entanto, esta operacionalização apesar de vantajosa do ponto de vista analítico traz alguns problemas quando analisamos as relações complexas existentes entre o Estado e a sociedade, ou mesmo quando conceptualizamos o Estado e o seu papel na sociedade.

Segundo Harris (2006), a sociedade civil pode ser entendida (1) como parte integrante do aparato do Estado, (2) como estrutura integrante de uma cultura de mercado e de direito de propriedade, (3) composta por organizações voluntárias e movimentos de ajuda que coexistem com o Estado e o mercado e (4) como um requisito democrático e da preservação do Estado de Direito no respeito pelos direitos humanos. Também Michael Edwards (2011) considera que entre as perspetivas radicais e neoliberais subjaz a universalidade da sociedade civil, quer sendo (1) um tipo de sociedade com normas próprias, (2) como parte da sociedade como um todo através de associações voluntárias que complementam/contrariam a ação do Estado e do mercado, ora (3) como um espaço de ação, cidadania e engajamento. Este debate teórico leva Michael Edwards (2011, p. 3) a considerar a sociedade civil no plano da "geometria das relações humanas", enquanto "padrões de ação coletiva e de interação que providenciam às sociedades respostas aos problemas de estrutura, autoridade, sentido e pertença, cidadania e gestão da coisa pública”. Neste sentido, a sociedade civil cobre uma série de organizações e entidades com diversas tipologias, propósitos e níveis de institucionalização, incluindo, entre outros, associações de bairro, movimentos sociais, grupos profissionais, organizações não-governamentais ou empresas sociais (Edwards, 2011, p. 5). Já a sua interação com o Estado e com o mercado pode também ter diferentes níveis e formas de mobilização e contestação em diversos contextos.

Mais profusamente, tem surgido nesta literatura o conceito de movimento social, enquanto estrutura que organiza a reivindicação em lutas políticas coletivas (Tarrow \& Tilly, 2009). Estas organizações permitem a aglomeração de capital social e político, possuindo contestação autónoma e servindo como intermediários políticos, tendo efeitos no esquema de balança de poderes e uma determinada orientação política, social e ideológica que se transforma em cosmovisão (Almond \& Verba, 1963; Walzer, 1992; Törnquist, 2009; Dagnino, 2011). Tal como consideram Della Porta e Diani (2011, p. 69), estes movimentos constituem-se "como redes informais criadas por uma multiplicidade de indivíduos, grupos e organizações, engajados em conflitos políticos ou culturais, conflitos esses baseados numa identidade coletiva partilhada". Desde sempre que a literatura sobre movimentos sociais se tem baseado no conflito histórico nascente no século Xıx e na centralidade do conflito nas sociedades pós-industriais e nas democracias emergentes, enquanto a literatura sobre sociedade civil tem enfatizado o consenso e a civilidade das relações entre público e privado (Cohen \& Arato, 1992; Tarrow \& Tilly, 2009; Della Porta \& Diani, 2011).

Desde a década de 1970 que a literatura tem sido inundada pelos "novos movimentos sociais", afastando-se dos movimentos sindicais e de trabalhadores e dos movimentos nacionalistas que dominaram as sociedades industriais, sem no entanto focar-se no novo sindicalismo, nos novos movimentos religiosos, ou ainda a impor- 
tância da autonomia e empoderamentos dos indivíduos face às estruturas do poder e a emergência do pós-materialismo e das novas divergências de classe (Inglehart, 1997; Della Porta \& Diani, 2011). Estes organizam-se em torno de campanhas, repertórios associativos e autorrepresentação pública (Tarrow \& Tilly, 2009).

Nas duas últimas décadas tem ressurgido na literatura sobre a América Latina, a necessidade de identificar e contextualizar o processo de redemocratização levado a cabo a partir da década de 1990 e depois da proliferação de regimes autoritários nas três décadas anteriores (O’Donnell, 1973; Mainwaring et al., 1992; Linz \& Stepan, 1996). Paralelamente ao debate acerca da consolidação das instituições democráticas através de estudos comparativos (Kitschelt et al., 2010), cresceu também a importância da identificação do movimento de redemocratização que crescera em força na década de 1980 e que levou ao derrube das ditaduras militares na década seguinte.

Seria entre as décadas de 1950 e 1990 que os movimentos sociais e a sociedade civil ganharam extrema importância, primeiro contra alguns regimes multipartidários, tal como aconteceu no Brasil com as crises do parlamentarismo (1961-4) ou no Chile na queda do governo de Salvador Allende, e depois com o esforço de redemocratização e de combate as políticas de reestruturação económico-financeira dos Estados latino-americanos com a crise das dívidas (Dagnino, 2011; Patrício, 2012). Nesse período, tem-se analisado o peso e o impacto da sociedade civil na democratização destes países, incluindo-se a sociedade civil como uma panaceia na resolução dos problemas das democracias recentes (Dagnino, 2011; Kenny, 2014). Este novo enfoque nas formas de ativismo político tem sido empiricamente enraizado nas diferenças de contexto apresentadas pelas novas democracias do sul com altos níveis de desigualdade social, uma cultura política de participação em movimentos sociais e desconfiança dos cidadãos face às instituições democráticas (Nohlen, 2002). Tal como considera Evelina Dagnino (2011), os altos níveis de desigualdade, a heterogeneidade cultural, o predomínio de mercados informais, a pobreza endémica e a estrutura democrática têm influência na forma da sociedade civil na América Latina. Mesmo o esforço conjunto contra o autoritarismo, acabou por se tornar fragmentado com a democratização e a multiplicação de fenómenos sociais e políticos. Aliás esta "unidade da sociedade civil" acontece meramente do ponto de vista normativo (Cohen \& Arato, 1992), apresentando-se o conflito e a heterogeneidade como elementos essenciais da sociedade civil latino-americana (Dagnino, 2011).

Também a organização social e o conflito interclassista criam e recriam fórmulas e repertórios diferentes de mobilização e contestação na relação entre movimentos sociais, o Estado e os partidos (Dagnino, 2011). Novas formas de participação cidadã e a criação de espaços públicos não-estatais permitem a multiplicação de novas formas de mobilização, quer através dos já famosos orçamentos participativos, quer na contestação às políticas de ajustamento económico e à formação de capital social a partir de movimentos de contestação às estruturas de poder e de injustiça (Dagnino, 2011). É aliás na contestação às políticas de caráter neoliberal que os movimentos sociais na América Latina se têm organizado em redes nacionais e internacionais, 
apelando ao fortalecimento da participação democrática, engajando com governos e partidos, participando no processo de decisão e redefinindo os conceitos de participação, contestação e mobilização (Stahler-Shock \& Vanden, 2011). Estes movimentos sociais encontram-se enraizados no próprio processo de consolidação democrática e não pretendem conquistar o poder, antes estabelecendo formas de contestação e de ação coletiva que pretendem o aprofundamento da democracia (Encarnación, 2003; Stahler-Shock \& Vanden, 2011). Paralelamente, estes movimentos desenvolveram um repertório próprio que tenta ultrapassar o significado do individualismo nas sociedades pós-modernas (Inglehart, 1997).

Estando ancorados no processo de democratização, os movimentos sociais estão em constante interação com o sistema político (Tarrow, 1994; Goldstone, 2003). Estes movimentos assumem um papel central entre as comunidades e os partidos, sendo formas de expressão de reivindicação popular. No caso brasileiro é reconhecível uma integração entre movimentos sociais, a esquerda e a política partidária, numa complexa rede de relações entre movimentos, movimentos e partidos/coligações e na relação com os governos e os partidos de governo (Levy, 2012). Neste sentido, os movimentos sociais situam-se entre a autonomia ideológica e o pragmatismo político, entre a resistência e a acomodação, entre o protesto e a negociação (Alvarez \& Escobar, 1992). Nesta rede, os movimentos sociais ganham apoios no combate prático de objetivos contextuais, mas afasta-os do debate utópico. Esta relação entre movimentos sociais e partidos tem a capacidade de determinar os objetivos, a estrutura organizativa e os modelos de mobilização dos primeiros, constrangendo a sua ação e, por vezes, "normalizando" os seus métodos (Goldstone, 2003).

As estruturas políticas e sociais também constrangem a mobilização e o radicalismo dos movimentos sociais, estando condicionados pelo sistema político onde interagem e participam. Tal como argumenta Mair (1990), a evolução histórica e sociológica dos partidos demonstra a adoção de estratégias de contextualização, ou seja, de mecanismos de aprendizagem institucional que lhes permitem chegar ou manter-se no poder. De acordo com Petras e Veltmeyer (2009), a relação entre partidos e movimentos sociais altera-se quando os primeiros chegam ao poder, levando a que os segundos passem a subordinar-se ao governo e às estruturas partidárias. Por seu turno, os partidos podem passar a oferecer apoio aos movimentos na sua relação com o Estado, apoiando-se novas formas de organização e contestação. Vejamos como evoluiu esta relação entre o PT e o MST, especialmente com a vitória eleitoral de Lula da Silva nas presidenciais de 2002.

\section{O Partido dos Trabalhadores e o Movimento Sem Terra:}

\section{da Relação Ideológica à Relação Pragmática}

Os partidos latino-americanos de esquerda que a partir de finais da década de 1990 têm ganho terreno eleitoral constituem bases sociais heterodoxas e complexas. $\mathrm{O}$ Partido dos Trabalhadores brasileiro é produto de uma mescla de grupos e movimentos, de onde se destacam membros da teologia da libertação, do novo sindica- 
lismo, intelectuais de diversas origens, trotskistas e grupos integrantes da luta armada contra a ditadura (Secco, 2011). Segundo André Singer (2010), a penetração dos movimentos sociais nas periferias das grandes e médias cidades e nas zonas de conflito rural constituem a base do PT ideologicamente "consolidado em torno de interesses organizados, de intelectuais e da classe média urbana progressista". O PT nasce, assim, do cruzamento original de movimentos, organizações e individualidades, que perpassam o legado do Partido Comunista Brasileiro e o período parlamentar que antecedeu a ditadura militar e onde a esquerda desenvolvimentista teve um papel preponderante na governação (Patrício, 2012; Bernardes, 2014).

A sociedade civil e os movimentos sociais no Brasil têm uma raiz própria que advém do seu contexto, do processo histórico e das dinâmicas do poder. A criatividade social brasileira está bem patente na relação entre uma democracia institucionalmente fraca face a uma sociedade civil fortemente enraizada (Encarnación, 2003). Se na década de 1960, a sociedade civil brasileira estava concentrada na melhoria das condições materiais, de saúde e educação, na décadas de 1970 e 1980 e com a ditadura militar, os movimentos sociais passaram a relacionar a sua atividade com o processo de democratização, incluindo-se por exemplo as Comunidades Eclesiais de Base orientadas pela Conferência do Episcopado Brasileiro (Encarnación, 2003; Avritzer, 2009). A estes juntar-se-iam organizações não-governamentais de defesa dos direitos das mulheres, dos homossexuais e dos afro-brasileiros. Paralelamente, o novo sindicalismo, que rompe com as antigas dinâmicas de cooptação do sindicalismo estatal, emerge com a CUT e os metalúrgicos de São Paulo, a CGT, a USI e a CONTAG. Destes grupos resultou a participação e a socialização de grupos de trabalhadores,

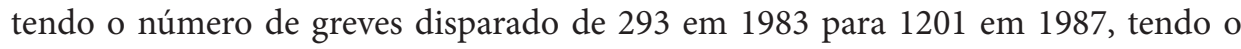
Brasil sido o país que mais dias de trabalho perdeu por 100,000 trabalhadores entre 1976 e 1987 (Encarnación, 2003). A organização de todos estes movimentos resultou numa vibrante sociedade civil durante todo o processo de transição que, ao não ter evoluído a partir de uma rutura institucional, permitiu a criação de coligações e redes entre movimentos (Encarnación, 2003; Avritzer, 2009). Em 2003 o nível brasileiro de densidade de vida associativa era superior ao de França ou Itália com apenas um terço dos brasileiros a não pertencer voluntariamente a associações (Encarnación, 2003).

A alteração do padrão associativo brasileiro demonstra que os movimentos e o associativismo não estão apenas ancoradas no processo histórico brasileiro, mas também nas respostas circunstanciais ao contexto político (Avritzer, 2009). O incentivo para esta alteração foi primeiramente o regime autoritário que encetou profundas transformações sociais e demográficas, num processo de urbanização e êxodo rural da sociedade brasileira sem o apoio de infraestruturas de educação, saúde e habitação nas grandes cidades do litoral (Cohen \& Rogers, 1995; Avritzer, 2009). Este fenómeno permitiu a criação de novos movimentos fundados na igualdade e na inclusão dos pobres na política, na defesa da distribuição de riqueza e de recursos públicos. Se entre as décadas de 1930 e 1980, a sociedade civil brasileira defendera a sua autonomia face ao Estado e aos partidos, num contexto de larga intervenção estatal, com o processo democrático o 
desejo de autonomia das organizações da sociedade civil passou a significar autonomia organizacional e administração de políticas sem o envolvimento do Estado (Avritzer, 2009). Tal como acontece com o movimento de saúde de São Paulo durante a década de 1980, os movimentos sociais propuseram formas de gestão local e territorial de várias políticas públicas independentes da ação do Estado (Encarnación, 2003).

Este âmbito autonómico dos movimentos da sociedade civil é ainda mais paradigmático em temáticas que envolvem a distribuição de rendimentos e terras, e agora mais recentemente, a transformação e transparência do sistema político. Na América Latina, a terra tem sido um dos elementos mais importantes na luta pela distribuição de riqueza e de poder, tal como é visível no conflito colombiano ou no processo de reforma agrária encetado pelos governos venezuelanos. O papel da terra na política latino-americana é essencial para se entender os processos socioeconómicos da sub-região, alimentando conflitos entre elites rurais, indígenas, camponeses, o Estado e as multinacionais agropecuárias (Teubal, 2009). São disso exemplo a fundação do Ejército Zapatista de Liberación Nacional, do MST ou da Confederación de Naciones Indígenas del Ecuador, movimentos com uma forte carga antiglobalização e anti sistémica face à indústria agrária e à desregulação do mercado (Carter, 2010).

Paralelamente, a representação de interesses rurais conservadores tem sido bastante coesa e forte no Congresso, com o controlo em vários mandatos de mais de um terço das bancadas. Esta coligação multipartidária designada de bancada ruralista, tem efeitos no acesso a recursos públicos com os grandes proprietários rurais a ter acesso a cerca de 1500 dólares por cada dólar recebido por uma família sem terra (Teubal, 2009; Carter, 2010). Por forma a ultrapassar este contexto, as organizações de camponeses organizaram desde 1987 cerca de 7100 ocupações de terras (Carter \& Carvalho, 2010). Os sucessivos governos têm sido sensibilizados para o problema da distribuição de terras, tendo o Estado distribuído parcelas de terreno a mais de oitocentas mil famílias entre 1985 e 2006, numa área total de 41 milhões de hectares (Carter, 2010). No entanto, apesar destes números impressionantes, o Brasil mantém-se em último lugar na distribuição de terra entre 16 países latino-americanos (Carter, 2010; Carter \& Carvalho, 2010).

O MST surgiu no seio da segunda vaga de mobilização do campesinato na América Latina, a meio de um processo de democratização. Esta segunda vaga de mobilização prende-se, por um lado, com os processos de democratização e, por outro lado, resultam de movimentos anti globalização, ou pelo menos, são críticos à forma de globalização que tem imperado (Teubal, 2009; Carter, 2010; Stahler-Shock \& Vanden 2011). Paralelamente, a luta pela distribuição de terras dependeu do estabelecimento de reformas agrárias, o que no caso do Brasil prestou-se desde o século XIX às lutas contra a oligarquia rural, o papel dos grupos de camponeses e na moderação e implementação estadual do processo com o desenvolvimento de políticas de desregulação e industrialização do setor agroalimentar ligado à estrutura de internacionalização da economia. Estas transformações já atrás citadas resultariam no aumento do trabalho assalariado, na precarização das condições de trabalho, nas ocupações de ter- 
ras, na expulsão de produtores de pequena e média dimensão, na massificação do êxodo rural, na monopolização e/ou oligopolização do mercado e na especulação financeira (Teubal, 2009).

Será com a nova constituição de 1988 que o MST ancorará legalmente as suas ações de ocupação de terras, através dos mecanismos da reforma agrária e da função social da terra inscritas constitucionalmente (Teubal, 2009; Welch, 2009). A inovação tática do MST corresponde à globalização do discurso dos novos movimentos sociais, organizados em torno de agências, advocacy networks e orientadas por redes multinacionais ou local e nacionalmente descentralizadas. Estas últimas procuram novos modelos de sociedade utilizando estratégias de ação direta, alterando estilos de vida e moldando processos formais de decisão, socialização política e feitura de leis (Norris et al., 2005). Estes movimentos organizam-se em redes descentralizadas de comunicação entre coligações e grupos, em estruturas relativamente horizontais e com relações informais de pertença (Keck e Sikkink, 1998; Norris, 2009; Sabetti, 2009; Teubal, 2009). No caso do MST, este tem apostado na mobilização de campanhas e marchas, participando no movimento do impeachment ao Presidente Collor em 1992, ou organizando longas marchas como a de Brasília em 1997, através de uma organização flexível, maior independência financeira e formas alternativas de socialização político-ideológica (Welch, 2009; Carter, 2010).

A relação do MST com o sistema político brasileiro é dinâmica e contextual, determinando as táticas utilizadas mas mantendo os valores simbólicos e os princípios políticos, não tendo um caráter antidemocrático (Teubal, 2009; Welch, 2009; Carter, 2010). Tal como consideram Norris (2009) e Carter (2010), o papel do MST insere-se no dos grupos populares engajados em processos de democratização que, contrários à luta armada, ao golpe ou ao motim, definem-se por formas não violentas, politizadas e autónomas de conflito social. Tenta, desta forma, ultrapassar o que entende como incongruência do processo institucional democrático (Tarrow \& Tilly, 2009).

Na década de 1990 o MST ganhou visibilidade mediática, enquanto o processo democrático brasileiro tinha já ultrapassado um impeachment presidencial e quatro planos de reestruturação económica, culminando no sucesso do Plano Real encetado pelo então ministro da fazenda Fernando Henrique Cardoso. A eleição presidencial deste último em 1993 e 1997 confirmou a consolidação da democracia brasileira e estabeleceu o modelo de desenvolvimento económico, aliás seguido pelos críticos do Partido dos Trabalhadores durante toda a década de 1990 (Singer, 2009; Bernardes, 2012; Patrício, 2012).

Desde o retorno da democracia que todos os presidentes desde José Sarney iniciaram reformas agrárias conservadoras, com o intuito de apaziguar conflitos rurais interclassistas, ao invés de promover políticas de apoio às famílias de agricultores e apostando no agronegócio como setor de apoio da estratégia de inserção internacional do Brasil (Patrício, 2012). Neste sentido, a distribuição de terras durante o novo período democrático tem continuado as políticas da ditadura militar, através da concessão de terras do Estado a setores privados e a multinacionais. 
A presidência de Fernando Henrique Cardoso multiplicou o número de acordos de terras especialmente durante o período de estabilização monetária quando o preço da propriedade rural baixou temporariamente (Carter, 2010). No entanto, estas novas comunidades de agricultores receberam pouco apoio estatal, mesmo depois da aprovação das leis de apoio agrícola concedido em forma de crédito, infraestruturas e outros serviços.

Seria nos mandatos de Cardoso (1994-2002) que o MST inicia uma campanha política de forte pendor contencioso e de mobilização, especialmente se tivermos em conta os massacres de Corumbiara com dez mortos e de Eldorado dos Carajás com 19 mortos e que alterariam a relação do governo FHC com o MST. Para o MST, os governos de FHC nunca olharam para o projeto de reforma agrária como algo sério, tendo antes subsidiado o agronegócio e privilegiado os setores exportadores. A tentativa de criminalizar a mobilização e as ocupações, foram seguidas pelos programas rurais inseridos na reestruturação económica na concessão de terras e nos subsídios à indústria agroalimentar suportados pelo Banco Mundial. No entanto, e também como considera FHC na sua autobiografia de 2006, a ocupação contínua de terras e os massacres de 1995 e 1996, a par do crescimento do agronegócio que substituía as formas tradicionais de latifúndio, tornaram impossível apoiar os processos de reforma agrária tal como defendidos pelo MST.

Neste cenário político conjuntural, a relação com o PT, com as suas raízes na fundação do partido, é natural do ponto de vista ideológico visto que ambas as organizações têm as mesmas origens grupais e políticas, encontravam-se ambos afastados do marxismo-leninismo e do sovietismo, para além de entrosarem durante muito tempo parte da sua mobilização com as comissões pastorais, a Teologia da Libertação e uma visão pós-modernista e radical, salpicada por movimentos trotskistas e neomarxistas (Secco, 2011; Bernardes, 2012, 2013; Patrício, 2012). Este entrosamento acontece também no plano da participação eleitoral de ativistas e líderes do MST em listas do PT do Rio Grande do Sul ou São Paulo.

Na década de 1990, o MST ganhou notoriedade mediática e passou a ver o PT como motor ideológico de diferentes movimentos sociais, dando corpo à sua ideologia de base. No entanto, desde cedo que os membros definiram uma linha de fronteira entre o partido e o ativismo do MST, firmando parcerias com o Estado e imprimindo uma lógica de autonomia organizativa com líderes do MST obrigados a deixar o MST caso assumissem posições de liderança no PT (Levy, 2012). Este cenário não deixou de lado o forte apoio dado pelo MST às diversas campanhas municipais do PT, com mobilização e participação em fora de discussões e comissões. Este cenário mudaria com a vitória eleitoral de Lula da Silva nas presidenciais de 2002.

\section{O MST e os Governos Lula}

Entre a campanha presidencial entre Lula da Silva e Collor de Mello nos inícios da década de 1990 e as eleições presidenciais de 2002, o PT alterou e muito a sua programática e o seu posicionamento ideológico, assemelhando-se a um partido social-de- 
mocrata. Estas transformações no PT corresponderam à necessidade de moderar o discurso petista, tornando-o mais pragmático, dando lugar a um partido de discurso amplo capaz de galvanizar não só a classe média urbana e escolarizada como parte da elite que não se revia no PT desde a sua fundação. André Singer (2009) considera que o partido percebera que a galvanização eleitoral das classes médias urbanas mais escolarizadas teria de ser acompanhado pela "normalização" do discurso, o que levaria à aliança com o Partido Liberal e à "Carta ao Povo Brasileiro" onde Lula da Silva apresenta-se como um candidato presidencial moderado. $\mathrm{O}$ discurso moderado e alargado permitiu a vitória em 2002, onde o voto do PT para o legislativo acompanha o voto de Lula; onde a aceitação das políticas económicas de Fernando Henrique Cardoso culmina com a adoção das novas leis da finança internacional; onde, após o controlo centralizador de José Dirceu e a profissionalização política, o PT finalmente atinge o epíteto de partido catch-all; onde o partido reconhece estrategicamente as forças que lhe tinham sido alheias desde 1989. No entanto, ficam ainda de fora as classes mais desfavorecidas, as mesmas que até 2006 tinham em toda a história do Brasil preferido apoiar partidos conservadores (Singer, 2009; Bernardes, 2013, 2014). Não é de somenos importância a formação de coligações no legislativo no sistema político brasileiro, onde perante a fragmentação partidária, os presidentes são levados a firmar acordos com partidos muitas vezes distantes do seu posicionamento ideológico inicial.

A evolução do PT no sistema partidário brasileiro acompanha uma estratégia de sobrevivência que tem raízes nas tendências da história do Brasil. O PT pragmatizou o seu discurso de forma a atingir diferentes eleitorados; mesclou-se internamente e externamente através de diferentes confluências ideológicas de esquerda e centro-esquerda, procurando alianças eleitorais transversais; tornou-se conservador ao conseguir o voto no Nordeste; transformou o Estado ocupando determinados setores (Bernardes, 2012).

A eleição de Lula em 2002 foi calorosamente aclamada por ativistas do MST, que viram descriminalizadas várias das ações diretas e ocupações cometidas durante a década de 1990. No entanto, Lula e o PT dependiam de certas bancadas parlamentares que acabaram por compor parte da coligação no legislativo (Patrício, 2012; Bernardes, 2012, 2013). Apesar do maior diálogo mostrado pelo novo governo e o aumento do financiamento público para o setor da agricultura familiar, o governo Lula deixou cair por terra as políticas de reforma agrária mais audaciosas que defendera durante as décadas de 1980 e 1990. Aliás, o número de beneficiários da reforma de terras foi menor nos governos Lula do que durante a administração de Fernando Henrique Cardoso, sendo que os primeiros apostaram 73\% da distribuição de terras na Amazónia (Carter, 2010). Com receio de represálias do setor agroindustrial, da bancada ruralista do Congresso e com o apoio da elite e das classes que suportam a estratégia de internacionalização da economia brasileira sufragada por Lula da Silva, o PT acabaria por incompatibilizar-se com o MST. A estratégia de exportação baseada em commodities e agrocombustíveis representou um apoio alargado do Estado 
sete vezes superior àquele dado aos agricultores familiares que representam $87 \%$ da mão-de-obra rural brasileira e produzem grande parte do comércio de produtos agrícolas consumidos no mercado nacional (Carter, 2010; Carter \& Carvalho, 2010).

Em 2004, o MST organizaria as “ocupações do Abril Vermelho" que acabariam por sair derrotadas judicial e politicamente com a aliança entre o governo de Lula e o setor agroindustrial (Welch, 2009). Confrontado com as opções de Lula, o MST aliou-se pragmaticamente ao PT numa tentativa de inserir a sua agenda de ocupações e ações na agenda política do partido. Esta aliança acontece com as franjas esquerdistas do PT também elas descontentes com as políticas encetadas logo no primeiro mandato de Lula entre 2003 e 2004 (Singer, 2009; Secco, 2011), ao mesmo tempo que encetou numa estratégia de apoio ao presidente. O movimento concentrou-se, assim, no combate às políticas agrícolas do ministro Roberto Rodrigues (Welch, 2009). Em 2006 o MST apoiaria Lula da Silva contra o candidato do PSDB José Serra, sem deixar de apoiar candidatos e ativistas em listas progressivas e esquerdistas do PT em vários estados brasileiros (Teubal, 2009; Welch, 2009; Carter, 2010).

A aliança do MST com as franjas esquerdistas do PT não alterou de forma alguma a identidade ideológica, simbólica, cultural e política do movimento. Pelo contrário, demonstra a sua contínua autonomia enquanto movimento social face ao Estado e aos partidos, tentando influenciar o partido de governo a partir das suas bases e do contacto com as estruturas do PT no governo, no Congresso, no Senado, nos estados e nas prefeituras (Carter, 2010). A estratégia de pressão política e de desobediência civil através de protestos, resistência passiva e ocupações pacíficas com negociações judiciais lentas não deixou de dar os seus frutos durante os mandatos de Lula. Além disso, o MST continua a possuir algumas redes de apoio no Estado com vários interlocutores no Ministério da Agricultura, no Banco do Brasil ou ainda no Ministério da Fazenda, com a estratégia de Lula da Silva de manter o diálogo com o movimento e de democratizar o acesso a recursos públicos através de programas rurais (Carter, 2010). A ocupação por membros do PT de cargos de chefia em diferentes ministérios, permitiu ao MST o acesso a financiamento para projetos em consórcios. Estes financiamentos permitiram o aumento da "institucionalização" das estruturas do movimento, com a profissionalização de alguns dos seus membros (Levy, 2012).

Paralelamente, o MST separou o lulismo do petismo, mantendo uma relação de galvanização com o primeiro. Esta galvanização passa pela personalidade incontornável do presidente Lula que manteve o seu poder mobilizador e pacificador das diferentes correntes do PT tanto à esquerda como à direita, representando ainda a face de um Brasil pobre e ideologicamente ancorado na emergência do novo sindicalismo da década de 1980. Os resultados eleitorais de Lula na presidência e do PT no legislativo diluem as contradições entre os dois movimentos. O encontro entre o estrato social e escolar dos votantes e a distribuição geográfica entre a eleição de Lula e dos deputados petistas é bastante aproximada; já para a reeleição de 2005 o cenário não se repete, o que leva André Singer a falar de um realinhamento eleitoral entre as eleições. Este realinhamento corresponde a uma alteração geográfica, ideológica e socioló- 
gica do voto em Lula. Na reeleição, Lula atinge os estratos mais pobres, tornando-se um símbolo da ascensão socioeconómica do Brasil. Não seria apenas a governação que alteraria este cenário, mas também o mensalão que, desertificando os apoiantes mais diretos de Lula como Dirceu, leva o presidente a isolar-se do PT e a utilizar a sua força de mobilização social e eleitoral entre as classes mais pobres. Ao alterar o tipo de mobilização eleitoral, Lula e o lulismo separam-se claramente do PT e do petismo, revisitando fenómenos históricos como o varguismo. Desta forma, a perda dos setores da classe média e das pessoas mais escolarizadas seria compensada pelo conservadorismo dos mais pobres, tal como o voto da esquerda seria compensado pelo crescimento do voto centrista e direitista (Bernardes, 2012).

Neste cenário eleitoral de 2005, o MST não deixou de apoiar Lula da Silva mesmo a meio de um escândalo de corrupção que abalou as estruturas do PT, diminuiu as hipóteses de reeleição e levou à condenação de elementos próximos de Lula e conotados com o centrismo do governo.

\section{Do Ideológico e do Pragmático}

Como considera Hochstetler (2008), a relação entre o MST e o PT durante os governos Lula contou com três fases distintas. Na primeira fase, o movimento usou do seu poder mobilizador para pressionar os setores conservadores do governo e apoiar Lula movendo o PT para a sua agenda ideológica. Neste campo, o MST articulou um discurso que opunha as elites tradicionais aos trabalhadores, ao mesmo tempo que procurou inserir-se institucionalmente através de parcerias governamentais. Na segunda fase, ressaltou as dúvidas, dentro do movimento campesino, quanto ao processo consultivo pelo qual o governo tentou estabelecer parcerias e formas de negociação. Finalmente, face à introdução da estratégia do agronegócio e das indústrias agropecuárias, o MST aponta as suas críticas ao governo enquanto apoiam Lula, mesmo contra as teses políticas e mediáticas que o colocavam no centro do mensalão (Levy, 2012).

Neste cenário evolutivo na relação com o PT e as estruturas do partido no governo, o MST adotou uma postura pragmática. Um governo que o MST esperava socialista e de pendor transformador das relações sociais, dos padrões de desigualdade e com uma nova cultura de fazer política, acabou por dar razão ao processo histórico das elites brasileiras e à cultura política de consenso que perpassa a institucionalização do sistema político e das instituições políticas (Bernardes, 2012). Na ligação entre partidos e movimentos sociais, o MST prova que é possível manter uma clara autonomia ideológica e organizativa, através de uma estratégia pragmática de inserção no sistema político (Alvarez \& Escobar, 1992). No entanto, o movimento não se afastou do seu debate utópico, tendo inclusive mantendo o seu processo de socialização, aprendizagem, programática, combate ao agronegócio e na defesa dos pequenos produtores através de redes internacionais que defendem a sustentabilidade agroalimentar. Contrariamente a Goldstone (2003) que considera a relação entre partidos e movimentos sociais como instrumental de parte a parte, o MST não normalizou o seu discurso nem os seus métodos, continuando a ocupação de terras mas agru- 
pando formas de profissionalização técnica na busca de financiamento público para projetos e consórcios (Petras \& Veltmeyer, 2009). Neste caso, não se observa o estabelecimento de relações de subordinação às estruturas partidárias, aliás mantidas pela autonomia organizativa do MST.

Aliás o realinhamento eleitoral entre 2002 e 2006 também produziu as dissidências na esquerda do PT. O Partido Socialismo e Liberdade (PSOL) e a campanha presidencial de Marina Silva são exemplos paradigmáticos de expulsões e dissidências provocadas logo no primeiro governo de Lula. Alguns líderes do MST apoiariam estas dissidências, posicionando-se ao lado do PSOL.

Esta estratégia de inserção pragmático-ideológica é demonstrada pela aposta do MST numa reforma agrária progressista e radical, contra a estrutura de internacionalização da economia brasileira também apoiada no setor agroindustrial. Paralelamente, o movimento encetou essa estratégia numa concertação pragmática com o PT mesmo depois de Lula da Silva ter frustrado a aliança com o MST e as políticas agrárias de apoio às classes sociais rurais desfavorecidas. Esta inserção estratégica das suas campanhas, orientações ideológicas e do seu repertório, demonstra que os movimentos e o associativismo não estão apenas ancoradas no processo histórico, mas também nas respostas circunstanciais ao contexto político (Avritzer, 2009). Apesar do MST ter perdido a luta contra o agronegócio com o governo PT, não deixou de defender a reforma agrária como caminho único, realista, pragmático e ideológico contra o processo monopolista do agronegócio.

Neste contexto, o MST não deixou de se preocupar com os aspetos da cooptação mantendo-se autónomo de outras esferas políticas mas sem deixar de participar no processo eleitoral, na dinâmica do processo político e na contestação e mobilização de ativistas pela ocupação de terras como direito constitucional. Frustrado com Lula, o MST procurou também novas formas de defesa da reforma agrária, articulando-se com aliados internacionais, solidificando a sua relação com a Via Campesina e ocupando outras terras com plantações produtivas como o eucalipto (Welch, 2009). Paralelamente, o MST entraria numa nova fase de organização e autonomização, dependendo menos de personalidades e lideranças, garantindo uma institucionalização mais sólida (Welch, 2009).

Data de receção: $14 / 11 / 2017$

Data de aprovação: 31/10/2019

\section{Referências}

Almond, G. \& Verba, S. (1963). The civic culture: Political attitudes and democracy in five nations. Princeton, NJ: Princeton University Press.

Alvarez, S. \& Escobar, A. (1992). Conclusion: Theoretical and political horizons of change in contemporary Latin American social movements. In A. Escobar \& S. Alvarez (Eds.), The making of social movements in Latin America (317-330). Boulder, CO: Westview Press. 
Avritzer, L. (2009). Civil society in Brazil: from state autonomy to political interdependency. Working Paper DCP/UFMG.

Bernardes, B.G. (2012). A história do Partido dos Trabalhadores: uma Narrativa Brasileira. Working Papers do Observatório Político, 19, 1 - 13.

Bernardes, B.G. (2013). A ascensão da esquerda na América Latina: os casos do PT no Brasil e do PSUV na Venezuela. Revista Portuguesa de Ciência Política, 3, 57-66.

Bernardes, B.G. (2014). Desenvolvimento na América Latina: Um modelo pragmático, Globo, 6, 106-111.

Blaikie, N. (2010). Designing social research. (2 $\left.{ }^{\mathrm{a}} \mathrm{ed}\right)$. Cambridge, Reino Unido: Polity Press.

Cardoso, F. H. (2006). A arte da política: A história que vivi. Rio de Janeiro, Brasil: Civilização Brasileira.

Carter, M. (2010). The landless rural workers movement and democracy in Brazil. Latin American Research Review, Special Issue.

Carter, M. \& Carvalho, H. M. (2010). A luta na terra: Fonte de inovação, fortalecimento e desafio constante ao MST. In M. Carter (Ed.), Combatendo a desigualdade social: $O$ MST e a reforma agrária no Brasil (287-330). São Paulo, Brasil: Editora da Universidade Estadual Paulista.

Cohen, J. \& Rogers, J. (1995). Associations and democracy. Londres, Reino Unido: Verso.

Cohen, J. \& Arato, A. (1992). Civil society and political theory. Cambridge, MA: MIT Press.

Costa, S. (2013). Sociedade civil, Estado e qualidade da democracia em Cabo-Verde: Entre a letargia cívica e a omnipresença do Leviathã. In C. M. Sarmento \& S. Costa (Eds.), Entre África e a Europa. Nação, Estado e democracia em Cabo Verde (273-329). Coimbra, Portugal: Almedina.

Dagnino, E. (2011). Civil society in Latin America. In M. Edwards (Ed.), The Oxford handbook of civil society (123-134). Oxford, Reino Unido: Oxford University Press.

Della Porta, D. \& Diani, M. (2011). Social movements. In M. Edwards (Ed.), The Oxford handbook of civil society. Oxford, Reino Unido: Oxford University Press.

Edwards, M. \& Gaventa, J. (2001) (Eds.). Global citizen action. Boulder, CO: Lynne Rienner Publishers.

Edwards, M. (2011). Introduction: civil society and the geometry of human relations. In M. Edwards (Ed.), The Oxford handbook of civil society (3-13). Oxford, Reino Unido: Oxford University Press.

Encarnación, O. G. (2003). The myth of civil society: social capital and democratic consolidation in Spain and Brazil. London, Reino Unido: Palgrave.

Faoro, R. (2001). Os donos do poder. A formação do patronato político brasileiro. (3a ed). São Paulo, Brasil: Globo.

French-Davis, R. (2005). Reforming Latin America's economies: after market fundamentalism. New York City, New York: Palgrave Macmillan.

Gilbert, A. (1994). The Latin American city. Londres, Reino Unido: Latin American Bureau.

Goldstone, J. A. (2003). Introduction. In J. A. Goldstone (Ed.), States, parties, and social movements (1-26). New York City, NY: Cambridge University Press. 
Harris, J. (2006). Development of civil society. In R. A. W. Rhodes, S. A. Binder \& B. Rockman, The Oxford handbook of political institutions (131-143). Oxford, Reino Unido: Oxford University Press.

Ingleghart, R. (1997). Modernization and post modernization: cultural, economic and political change in 43 societies. Princeton, NJ: Princeton University Press.

IPEA (2005). Radar social. Brasília: Instituto de Pesquisa Económica Aplicada.

Keck, M. \& Sikkink, K. (1998). Activists beyond borders: advocacy networks in international politics. Ithaca, NY: Cornell University Press.

Kenny, M. (2014). Civil society. Encyclopædia Britannica. Inc. Online.

Kitschelt, H., Hawkins, K. A., Luna, J. P., Rosas, G. \& Zechmeister, E. J. (2010). Latin American party systems. Cambridge, Reino Unido: Cambridge University Press.

Levy, C. (2012). Social movements and political parties in Brazil: expanding democracy, the "struggle for the possible" and the reproduction of power structures. Globalization, 9 (6), 783-798.

Linz, J. \& Stepan, A. (1996). Problems of democratic transition and consolidation: Southern Europe, South America, and post-communist Europe. Baltimore, MD: Johns Hopkins University Press.

Mainwaring, S., O'Donnell, G. \& Valenzuela, S. (1992). Issues in democratic consolidation: the new South American democracies in comparative perspective. Notre Dame, IN: Notre Dame University Press.

Mair, P. (1990) (Ed.). The West European party system. Oxford, Reino Unido: Oxford University Press.

Malamud, A. (2009). Fragmentação e divergência na América Latina. Relações Internacionais, 24, 61-73.

Munck, G. (2007). Regimes and democracy in Latin America. Oxford, Reino Unido: Oxford University Press.

Nohlen, D. (2002). Political participation in new and old democracies. Voter turnout since 1945: a global report, IDEA.

Norris, P. (2009). Political activism: new challenges, new opportunities. In C. Boix \& S. Stokes (Eds.), The Oxford handbook of comparative politics (628-649). Oxford, Reino Unido: Oxford University Press.

Norris, P., Walgrave, S. \& Van Aelst, P. (2004). Who demonstrates? Anti-state rebels, conventional participants, or everyone. Comparative Politics, 37 (2).

O'Donnell, G. (1973). Modernization and bureaucratic-authoritarianism: studies in South American politics. Berkeley, CA: University of California Press.

Patrício, R. (2012). Estudos de área: América Latina. Lisboa, Portugal: ISCSP.

Petras, J. \& Veltmeyer, H. (2009). What's left in Latin America?. Farnham, Reino Unido: Ashgate Publishing.

Rodgers, D., Beall, J. \& Kanbur, R. (2012)(Eds.). Latin American urban development into the $21^{\text {st }}$ Century: towards a renewed perspective on the city. Londres, Reino Unido: Palgrave Macmillan. 
Sabetti, F. (2009). Democracy and civic culture. In C. Boix \& S. Stokes (Eds.), The Oxford handbook of comparative politics (628-649). Oxford, Reino Unido: Oxford University Press.

Secco, L. (2011). A história do PT. São Paulo, Brasil: Ateliê Editora.

Singer, A. (2009). Raízes sociais e ideológicas do lulismo. Novos Estudos, 85, 83-102.

Singer, A. (2010). A segunda alma do partido dos trabalhadores. Novos Estudos, 88, 89-111.

Stahler-Shock, R. \& Vanden, H. (2011). Introduction: a second look at Latin American social movements' resistance to the neoliberal paradigm. Latin American Perspectives, 38 (1), 5-13.

Tarrow, S. (1994). Power in movement: collective action and politics. Cambridge, Reino Unido: Cambridge University Press.

Tarrow, S. \& Tilly, C. (2009). Contentious politics and social movements. In C. Boix \& S. Stokes (Eds.), The Oxford handbook of comparative politics (435-460). Oxford, Reino Unido: Oxford University Press.

Teubal, M. (2009). Agrarian reform and social movements in the age of globalization: Latin America at the dawn of the twenty-first century. Latin American Perspectives, 36 (4).

Törnquist, O. (2009). Introduction: the problem is representation! Towards an analytical framework. In O. Törnquist, N. Webster \& K. Stokke (Eds.), Rethinking popular representation (1-27). Londres, Reino Unido: Palgrave Macmillan.

Walzer, M. (1992). The civil society argument. In C. Mouffe (Ed.), Dimensions of radical democracy: pluralism, citizenship, community (89-107). Londres, Reino Unido: Verso.

Welch, C. (2009). Camponeses: Brazil's peasant movement in historical perspective (19462004). Latin American Perspectives, 36 (4), 126-155.

WORLD BANK (2005). World Development Report 2006: Equity and Development. Washington, D.C.: World Bank.

\section{Sobre o autor}

Bruno bernardes é Doutorando em Ciência Política pelo ISCSP-ULisboa, mestre em Ciência Política pela Universidade de Estocolmo. Exerce atualmente funções como Vogal Secretário da Junta de Freguesia de São Domingos de Rana com os pelouros da ação social, saúde e juventude.

\section{About the author}

BRUNO BERNARDES is a PhD student in Political Science at Lisbon University; master's degree in Political Science from Stockholm University. He is currently working as alderman at São Domingos de Rana Local Parish. 